\title{
Perceptions of Administrative and Supervisory Support in Public Child Welfare
}

\author{
Tonya M. Westbrook \\ Josie Crolley-Simic
}

\begin{abstract}
Using the Child Welfare Organizational Culture Inventory (CWOCI) in a public child welfare agency, perceptions of administrative and supervisory support held by employees with social work degrees (BSW and MSW) were compared to perceptions of administrative and supervisory support held by employees without social work degrees. Child welfare employees with social work degrees reported lower administrative and supervisory support than employees without social work degrees. Implications for social work educators, public child welfare administrators and supervisors, and future research are presented.
\end{abstract}

Keywords: Child welfare workforce, administrative support, supervisory support, social work education

America's public child welfare system investigated 3.7 million reports of child abuse and/or neglect in 2008, finding that 772,000 children were victims of abuse, neglect, or both (U.S. Department of Health and Human Services, Administration on Children, Youth, and Families, 2010). Employees of the public child welfare system are responsible for determining the validity of child abuse and neglect reports, determining the safety of potential victims of abuse and neglect, making decisions about removal of children from their homes and placements in foster care and other out-of-home settings, and providing abuse/neglect prevention services (Crosson-Tower, 2002; Knudsen, 1988; Samantrai, 2004). Researchers have found the public child welfare workforce has been inexperienced, undereducated, and inadequately trained and has been plagued with high turnover rates and low employee retention (Cyphers, 2001; Dickinson \& Perry, 2002; Drake \& Yadama, 1996; Ellett, Ellett, \& Rugutt, 2003; General Accounting Office $\{\mathrm{GAO}\}$, 2003). Turnover rates in public child welfare agencies have been estimated to be between 20\% and 40\% annually (American Public Human Services Association, 2005; Cyphers, 2001; GAO, 2003), with turnover rates over two-year periods as high as $90 \%$ (Drake \& Yadama, 1996). These workforce problems have overwhelmed the child welfare system, ultimately diminishing the quality of services provided to children and their families (Cyphers, 2001; GAO, 2003).

Causes associated with high turnover in public child welfare include inadequate supervision, lack of supervisory support, and lack of training (Cyphers, 2001; Ewalt, 1991; GAO, 2003; Samantrai, 1992). A costly implication of high turnover has been the large number of caseworkers assigned to each supervisor. In turn, supervisors have not been able to provide adequate supervision. This deficit in supervision may be especially problematic for new workers who need adequate mentoring and support to learn to perform such a complex job. Another implication of high turnover is that workers are

\footnotetext{
Tonya M. Westbrook, Ph.D., is an Assistant Professors and Josie Crolley-Simic, Ph.D., is an Associate Professor, both in the Department of Social Work at Western Carolina University in Cullowhee, NC. This work was supported by the U. S. Administration for Children and Families.
}

Copyright (C) 2012 Advances in Social Work Vol. 13 No. 3 (Fall 2012), 603-617 
often promoted to supervisory positions within three years of beginning employment, providing child welfare agencies with a cadre of inexperienced supervisors (GAO, 2003).

One way the child welfare system has responded to high turnover is to reprofessionalize the field by increasing the number of employees with social work degrees with the purpose of hiring workers who would remain in the job longer and be better prepared for the job tasks than persons without social work degrees (Barbee et al., 2009a; Dickinson \& Perry, 2002; Landsman, 2001). Research indicated that child welfare employees with social work degrees were more satisfied in their jobs (Barth, Lloyd, Christ, Chapman, \& Dickinson, 2008), more effective in their jobs (Barbee et al., 2009a), and were more dedicated to the field of child welfare (Curry, McCarragher, \& DellmanJenkins, 2005) than employees without social work degrees. To better understand employees in this overburdened system it is important to investigate employees' perceptions of administrative and supervisory support, with particular attention to possible differences in perceptions of employees with social work degrees and employees without social work degrees.

\section{LITERATURE REVIEW}

This section will discuss significant literature in the areas of administrative and supervisory support for child welfare workers. Also included was a review of differences between public child welfare employees with social work degrees and those without social work degrees in effectiveness, job satisfaction, and retention and turnover.

\section{Administrative Support in Public Child Welfare Agencies}

The role of child welfare administrators has been given much less attention by researchers than that of front line supervisors. Administrative support has been linked to child welfare employees' commitment to the job and correlated with workers' intentions to remain employed in the field (Ellett, 2000). Samantrai (1992) reported varying employee views of administrators, with some employees finding administrators to be "doing the best" they could while others viewed administrators as "nonsupportive and adversarial" (p. 455). Other studies have indicated that employees would like to have more input regarding policy decisions made by administrators (Lieberman, Hornby, \& Russell, 1988) and that administrators focused more attention on policy implementation than on practice with families and children (Ellett, Ellis, Westbrook, \& Dews, 2007; Westbrook, Ellis, \& Ellett, 2006).

The characteristics of effective administrators were reported in a study using focus groups of child welfare employees who had been employed in the field for at least eight years (Westbrook et al., 2006). The most effective administrators were characterized as accessible, helpful, supportive, caring, flexible, knowledgeable, experienced, and understanding of the daily activities taking place in the agency. Good administrators were also described as those who worked to promote a positive public image of the agency; were quick to respond to agency vacancies, using creative resolutions when necessary; and served as a buffer between the local public child welfare staff and outside entities

such as the community and state level administrators and leaders. Good administrators 
were both trustworthy and trusting of their employees and the decisions their employees made; gave priority not only to clients, but also to agency employees as well; valued the professional development of employees; placed a greater emphasis on people than on agency policies; and promoted an atmosphere of teamwork in which employees developed a sense of responsibility for each other. Effective administrators were seen as an essential element of an organizational culture that generates long term employees (Westbrook et al., 2006).

\section{Supervisory Support in Public Child Welfare Agencies}

Supervisors tend to be more involved in employees' daily jobs than administrators; consequently, the supportive relationships with employees may be different than those of administrators and were critical to employee retention, morale, and job satisfaction (American Public Human Services Association, 2005; Cyphers, 2001; Dickinson \& Perry, 2002; Ellett, Ellett, \& DeWeaver, 2007; GAO, 2003; Rycraft, 1994; Samantrai, 1992). Public child welfare employees have reported that having a supportive supervisor was important in assisting them through poor working conditions. On the contrary, supervisors described as critical, unsupportive, and uncaring can make working conditions intolerable (Samantrai, 1992). A recent nationwide study (Barth et al., 2008) found the strongest predictor of job satisfaction among public child welfare employees to be quality of supervision. Interestingly, child welfare employees generally perceive their supervision as high in quality, with those holding social work degrees reporting more satisfaction with supervision than those with other types of degrees (Barth et al., 2008).

Supportive supervisors have been described in numerous studies (APHSA, 2005; Barth et al., 2008; Dicksinson \& Perry, 2002; Ellett et al., 2003; Rycraft, 1994; Samantrai, 1992). Supportive supervisors are considered to be those who are caring, helpful, sympathetic, available, good listeners, flexible, and respectful. Supportive supervisors also provide emotional and instrumental support. Quality in supervision includes understanding the responsibilities and demands placed on front line workers, providing fair and equitable distribution of workload, and being knowledgeable of the child welfare system and daily child welfare practice (Dickinson \& Painter, 2009; Lee, Forster, \& Rehner, 2011; Miseung, 2010; Scannapieco \& Connell-Carrick, 2007). Good supervisors treat their employees like professionals; provide information to employees to help them improve their skills; set high, but realistic expectation for their employees; and offer praise to employees when it is deserved. It has been suggested that supervisors can also increase employee retention by offering clear incentives for high quality job performance; providing emotional support in addition to case guidance; encouraging continuing education; promoting efforts to increase staff morale; helping employees develop effective, constructive coping skills; and encouraging enthusiasm for the job (Dickinson \& Painter, 2009; Lee et al., 2011; Miseung, 2010; Scannapieco \& ConnellCarrick, 2007).

\section{Child Welfare Employees With and Without Social Work Degrees}

In the past, a social work degree, most often a MSW, was the preferred minimum qualification for caseworkers in child welfare; by 2000 a BSW was required in only four 
states and a MSW was required of supervisors in only two states (Steib \& Whiting Blome, 2003). Today most child welfare agencies require only a bachelor's degree in any field; only about one quarter of child welfare services are provided by caseworkers with a BSW or MSW (Steib \& Whiting Blome, 2003). In 1987, 15\% of child welfare employees held a BSW degree, 13\% held a MSW degree, while 56\% had a non-social work bachelor's degree and 13\% had a non-social work graduate degree (Lieberman et al., 1988). The number of child welfare workers with social work degrees increased slightly by 2008 to $39.5 \%$, lowering the number of public child welfare workers with non-social work bachelor's degrees to $48.8 \%$ (Barth et al., 2008).

Among professionals in public child welfare, it is widely believed that it is imperative that efforts be made to recruit and retain professionally educated employees with social work degrees for public child welfare systems (Barbee et al., 2009b; Dickinson \& Perry, 2002; Risley-Curtiss, 2003). Over the last several years, many efforts have been made to increase the number of social work degreed employees and specifically social work degreed employees with education and training in public child welfare through the use of Title IV-E funded programs (Barbee et al., 2009b). Several studies have found relationships between the type of degree child welfare workers hold and various factors of importance to the field including effectiveness, job satisfaction, and retention.

Degree and effectiveness of work. Numerous studies have found that child welfare employees with a social work degree were more competent and effective in their jobs than employees with other degrees or no degree (Child Welfare League of America, 1998; Dhooper, Royse, \& Wolfe, 1990; Scannapieco \& Connell-Carrick, 2007). In a study comparing child welfare employees with Title IV-E training to other employees, Barbee et al. (2009a) found several differences in the two groups. For example, workers with IV-E training were more likely to accept a report as an investigation, were more aggressive in case interventions, were more likely to substantiate a report of child abuse and/or neglect, were more likely to accurately assess risk of harm, and were more likely to provide continuing services to families more often. Furthermore, IV-E trained workers were more cost efficient at their jobs and more likely to place foster children with relatives rather than in foster homes and residential facilities; IV-E workers made more adoptive home placements and used fewer emergency placements. These workers visited foster children on their caseloads more often, and more often established a permanency plan for foster children in their caseload than did workers without IV-E training. Foster children in caseloads of employees in this study without IV-E education had longer stays and more moves within the foster care system than foster children whose workers held a IV-E education (Barbee et al., 2009a).

Degree and job satisfaction. Studies have also found that public child welfare employees with social work degrees are more satisfied in their jobs than those without social work education (Barbee et al., 2009b; Barth et al., 2008). Barth and colleagues (2008) found that those with non-social work undergraduate degrees were less satisfied in the job than those with a BSW degree, a MSW degree, or any graduate degree. Of those public child welfare employees in this study with a bachelor's degree, those with a BSW 
were more satisfied than those employees with a non-social work bachelors degree (Barth et al., 2008).

Degree and turnover/retention. Numerous studies have posited that the overall lack of social work degreed employees is a contributing factor in child welfare turnover and that improved employee retention is related to social work degree or Title IV-E supported social work education among child welfare staff (Dickinson \& Perry, 2002; Ellett et al., 2003; Robin \& Hollister, 2002; Rycraft, 1994; Scannapieco \& Connell-Corrick, 2003). However, employee retention studies have found mixed results. In a recent study, Barbee and colleagues (2009b) evaluated Kentucky's Public Child Welfare Certification Program (PCWCP) and ten years of BSW graduates of the program. Those who completed the PCWPC child welfare social work education program reported feeling highly prepared for the job, had high levels of commitment to the field of public child welfare and had increased retention over a two-year period as compared to those who entered child welfare employment without PCWCP training. However, the study also found a drop in retention at the four-year mark for PCWCP graduates (Barbee et al., 2009b). Dickinson and Painter (2009) found employees with BSW and BA degrees were less likely to leave their jobs than employees with MSW degrees. Strolin-Goltzman, Auerbach, McGowan, and McCarthy (2008) found that employees having a social work degree and working in an urban area were more likely to leave than employees in urban areas without social work degrees. Auerbach, McGowan, and Heft LaPorte (2008) also found employees with MSW degrees were more likely to leave child welfare employment than those without a social work degree.

The above literature review demonstrates the importance of administrative and supervisory support in public child welfare It examines many studies over the past several years that have found connections between supervisory and administrative support and employees' satisfaction, morale, and retention in public child welfare jobs. Moreover, the literature review examines research finding that employees with social work degrees provide more effective services to children and their families in public child welfare. This highlights the importance of hiring and retaining employees with social work degrees. These ideas provide the rationale for the current study: to examine differences in administrative and supervisory support as perceived by employees with and without social work degrees in an effort to determine if employees with social work degrees need additional support in order to raise job satisfaction and intentions to remain on the job so that those with the best education for the work are more likely to remain in the job.

\section{Purpose of the Study}

Given the importance of administrative and supervisory support, the purpose of this study was to examine differences in employees' perceptions of administrative and supervisory support in a southern state's public child welfare system as reported by employees with social work degrees compared to employees without social work degrees. This study was part of a larger research project involving examination of organizational culture and child welfare employees' intentions to remain in their jobs. The data set for the analyses completed for this study was the same as that used in prior research 
(Westbrook, Ellett, \& DeWeaver, 2009). Institutional Review Board Approval for the study was obtained (project approval number 2005-10756) before the following study procedures were initiated/completed.

\section{METHODOLOGY}

\section{Sample}

This study was part of a larger research project that examined organizational culture in a statewide public child welfare system. More detailed information about the study, the sample, and the survey can be found in Westbrook, Ellett, and DeWeaver (2009). The sample for the larger research project of which this study was a part was defined as all caseworkers, supervisors, and administrators employed in a southern state's one hundred fifty-nine county Department of Family and Childrens Services (DFCS) offices who provided services to maltreated and alleged maltreated children and their families. Due to vacant positions and ever changing staff allocation figures, the exact number of DFCS employees in the population for this study could not be determined. However, according to the most recent DFCS staffing allocation statistics available prior to this study, the agency was allocated to employ 3,227 individuals in child welfare caseworker, supervisor, and administrator positions across the state.

In general, most respondents were female (872 or $84.4 \%$ ), with males accounting for only $12 \%$ (124) of the sample. Most respondents were Caucasian (617 or 59.7\%) or African American (373 or 36.1\%) with ages fairly evenly distributed (34.2\% being 30 years old or younger; 34.6 being 41 years old or older, and 29.5\% between the ages of 31 and 40). Most respondents in this study were frontline caseworkers/case managers (763 or $73.9 \%)$. Supervisors made up $16.6 \%$ (171) respondents and $6.8 \%$ (70) respondents were county office level administrators. A large portion of respondents reported possessing non-social work baccalaureate degrees (569 or 55.1\%) and non-social work master's degrees (127 or $12.3 \%$ ). Only $24.3 \%$ of respondents possessed a social work degree; $164(15.9 \%)$ of those possessed a baccalaureate of social work degree and 87 (8.4\%) possessed master's of social work degrees. Only 75 (7.3\%) respondents reported no four-year college degree (44 or $4.3 \%$ with a high school education or GED only, and 31 or $3 \%$ with an associate or two year degree). Two respondents $(0.2 \%)$ reported having non-social work doctoral degrees.

As previously reported in Westbrook, Ellett, and DeWeaver (2009), 3227 surveys were sent to child welfare workers; a total of 1,123 surveys were returned and subsequently scanned into a data file. Surveys from 90 respondents were excluded from the data analyses (23 from DFCS employees in positions other than child welfare services such as Adult Protective Services and the Office of Family Independence, and 67 with excessive missing data). Surveys were removed from analysis for missing data if nine or more item responses $(10 \%)$ were missing on the Child Welfare Organizational Culture Inventory or if more than one item response was missing from the Intent to Remain Employed measure. Removal of surveys from data analysis that were missing 10 percent or more of responses allowed for analysis to be completed without using statistically generated answers for missing data. This procedure also did not severely impact the 
return rate or number of surveys available for data analysis. These procedures resulted in a final return rate of $32 \%$ ( $n=1,033$ usable surveys). It should be noted that this return rate was not exact. The return rate percentage (32\%) was calculated for 3,227 potential DFCS child welfare employees. The return rate was somewhat lower than desired. However it is important to note that the demographic results, with few exceptions, reasonably mirrored those of other recent, large sample, statewide workforce studies in the state (Ellett et al., 2003; Ellis, Ellett, \& DeWeaver, 2007).

\section{Study Measures}

Participants of this study were asked to answer ten demographic questions (providing information regarding subjects' county of employment, position and work assignment, gender, age, ethnicity, education, number of years of child welfare work experience, caseload size, and number of persons for which supervisory and administrative participants provide supervision), complete the Child Welfare Organizational Culture Inventory (CWOCI), and complete the Intent to Remain Employed-Child Welfare scale (Ellett, 2000). This study was part of a larger study that included scales not relevant to the study reported here (Westbrook et al., 2009).

The CWOCI is an 84 item self-report measure of organizational culture in public child welfare agencies. Each item is responded to using a forced-choice four-point Likert scale $(1=$ Strongly Disagree, $2=$ Disagree, $3=$ Agree, $4=$ Strongly Agree). Principal Components Analysis procedures determined that the CWOCI consists of seven dimensions; this study focused on two dimensions, Administrative Support and Supervisory Support. The Administrative Support subscale consists of 10 items and has been found to have a Cronbach's alpha coefficient of internal validity of .94. The Supervisory Support subscale consists of 20 items with a Cronbach's alpha coefficient of .97 (Westbrook et al., 2009). The conceptual definitions of Administrative Support and Supervisory Support used in this study are explicated below.

Definition of administrative support. Administrative Support refers to the frequency and quality of professional child welfare staff's interactions and relationships with agency heads that frame, encourage, and reward persistence, commitment, and excellence in professional practice. Administrative Support is evidenced in the agency in several ways such as the quality of interpersonal relationships between administrators and subordinates; development, explication, and enforcement of rules and policies; administrative guidance and leadership; and the provision of resources. Examples of Administrative Support include administrators ensuring their staff have adequate resources (supplies and equipment) to complete their work and showing concern and sensitivity to staff needs and feelings (Westbrook et al., 2006).

Definition of supervisory support. Supervisory Support refers to the frequency and quality of professional child welfare staff's interactions and relationships with immediate superordinates that frame, encourage, and reward persistence, commitment, and excellence in professional practice. Supervisory Support is evidenced in the agency in several areas such as the quality of interpersonal relationships between supervisors and subordinates; internal and external advocacy on behalf of staff and clients; explanation of 
and monitoring of compliance with rules and policies; work assignments and professional decision making; and personal and organizational professional development, learning, and guidance as seen in mentoring and job orientation. Examples of Supervisory Support are supervisors' recognition and rewards for workers' quality work, helping, advocating for, mentoring their workers when needed, and recognizing individual workers' strengths and needs (Westbrook et al., 2006).

\section{Data Collection Procedures}

Survey packets were created for all 3,227 potential participants (plus an additional $10 \%$ overage to cover miscalculations in staffing allocation, lost surveys, etc) and were mailed to county office directors with a request to distribute the packets to all child welfare employees. Each packet contained a demographic questionnaire, the Child Welfare Organizational Culture Inventory (Westbrook et al., 2009), and the Intent to Remain Employed - Child Welfare measure (Ellett, 2000) all in a scannable format. A follow-up reminder letter was sent three weeks after the surveys were mailed and a second reminder letter was mailed two weeks after that.

\section{Data Analysis}

Descriptive statistics (frequencies and percentages) were computed for the demographic characteristics of the sample. Means and standard deviations were calculated for the Administrative Support and Supervisory Support factored dimensions of the Child Welfare Organizational Culture Inventory as reported by those with social work degrees (BSW and MSW) and those without social work degrees. A two-tailed t test was computed to explore statistically significant differences between social work (BSW and MSW) and non-social work degree groups. All statistical analysis was performed using SPSS version 14.

\section{RESULTS}

\section{Comparisons of Social Work Degree and Non-Social Work Degree Groups}

Descriptive statistics (means and standard deviations) were computed for the two subscales of the CWOCI used in this study for respondents with and without social work degrees. Administrative Support was found to have a mean score of 26.38 (SD 6.65) for those with social work degrees and a mean score of 27.37 (SD 5.28) for those without social work degrees. Supervisory Support was found to have a mean score of 56.62 (SD 11.59) for those with social work degrees (BSW and MSW) and a mean score of 58.50 (SD 9.18) for those without social work degrees. The maximum possible scores for the two subscales were 40 and 80 respectively. The results of these comparisons are shown in Table 1.

Two tailed t tests were computed to explore statistically significant differences between social work (BSW and MSW) and non-social work (all other) degree groups on the Administrative Support and Supervisory Support factors of the CWOCI. Statistically 
significant differences between the two degree groups were evident for both Administrative Support $(\mathrm{t}(1022)=-2.409, \mathrm{p}<.05)$ and Supervisory Support $(\mathrm{t}(1022)=$ $-2.69, \mathrm{p}<.05)$. The mean difference between the two groups for Administrative Support was -.99 favoring the non-social work degree group. The mean difference between social work and non-social work degree groups for Supervisory Support was -1.88 favoring the non-social work degree group.

Table 1: $\quad$ Summary of $t$ Test Comparisons Between Social Work (BSW and MSW) and Non-Social Work Degree Groups for Supervisory Support and Administrative Support Factored Dimensions of the Child Welfare Organizational Culture Inventory Factor

\begin{tabular}{|c|c|c|c|c|c|c|c|}
\hline \multirow[b]{2}{*}{ CWOCI Factor } & \multicolumn{2}{|c|}{ BSW/MSW } & \multicolumn{2}{|c|}{$\begin{array}{c}\text { Non-Social } \\
\text { Work Degree }\end{array}$} & \multirow[b]{2}{*}{$\begin{array}{c}\text { Mean } \\
\text { Difference }^{\mathrm{a}}\end{array}$} & \multirow[b]{2}{*}{$\mathrm{t}$} & \multirow[b]{2}{*}{$\mathrm{p}$} \\
\hline & Mean & SD & Mean & SD & & & \\
\hline Supervisory Support (20) ${ }^{\mathrm{b}}$ & 56.62 & 11.59 & 58.50 & 9.18 & -1.88 & -2.692 & .009 \\
\hline Administrative Support (10) & 26.38 & 6.65 & 27.37 & 5.28 & -0.99 & -2.409 & .016 \\
\hline \multicolumn{8}{|c|}{$\begin{array}{l}{ }^{a} \text { Mean difference score calculated by subtracting non-social work degree mean from BSW/MSW degree } \\
\text { mean. } \\
{ }^{b} \text { Number of items in factored dimension }\end{array}$} \\
\hline
\end{tabular}

\section{DISCUSSION AND IMPLICATIONS FOR SOCIAL WORK}

This study examined administrative and supervisory support as reported by employees in a southern state's public child welfare system using two subscales of the CWOCI. These subscales measured child welfare workers' perceptions of the administrative and supervisory support they received. Comparisons were made between the perceptions of child welfare employees with social work degrees and employees without social work degrees. The results indicated child welfare employees with social work degrees perceived less support from administrators and supervisors in the agency than employees without social work degrees perceived. This section will discuss this finding in relation to current research on administrative and supervisory support.

This is the first known study to examine differences in how public child welfare employees with social work degrees and employees without social work degrees perceive both administrative and supervisory support. Several prior studies have focused on examining and describing good supervisory (APHSA, 2005; Barth et al., 2008; Dickinson \& Perry, 2002; Ellett et al., 2003) and administrative support (Ellett, 2000; Ellis et al., 2007; Lieberman et al., 1988; Samantrai, 1992). Other studies have found links between supervision and employee retention, morale, and job satisfaction (APHSA, 2005; Cyphers, 2001; Dickinson \& Perry, 2002: Ellett et al., 2003). Also research studies suggest that child welfare employees with social work degrees are more effective in their 
jobs (CWLA, 1998; Scannapieco \& Connell-Carrick, 2007) and are more satisfied with their jobs (Barbee et al., 2009b; Barth et al., 2008). Numerous studies have examined the relationship between degree type (social work degree and non-social work degree) and retention or turnover. The results of these studies have been mixed with some finding social work degreed employees more likely to remain in their jobs (Dickinson \& Perry, 2002; Ellett et al., 2003; Scannapieco \& Connell-Carrick, 2003) and others finding that employees with social work degrees are more likely to leave their jobs (Auerbach et al., 2008; Strolin-Goltzman et al., 2008). In summary, supervisory and administrative support is important in retaining child welfare workers (Dickinson \& Perry, 2002; Ellett et al., 2003; GAO, 2003) and the number of child welfare workers with social work degrees has risen over the years (Barth et al., 2008). The perception of supervisory and administrative support could very well be important in retaining these employees.

The results of this study should be understood within the context of some strengths and limitations. First, this survey was administered to a statewide public child welfare system with every employee in the statewide system having an opportunity to participate. Second, although the study was completely voluntary, it was supported by the director of the statewide public child welfare agency. A letter from the director, indicating her support and requesting that all employees complete and return the study, was included with the survey for all participants. Finally, the pen and paper style survey provided in a scannable format was found through a time and clarity study (Westbrook et al., 2009) prior to this administration to take only about twenty minutes to complete, making it fairly easy for all employees to be included. The study should be considered in the light of several limitations as well. First, participation was completely voluntary and responses to the surveys should be considered in that light. Thus, it is possible that those employees choosing not to participate in the study might be more dissatisfied (or satisfied) with the agency than those who did complete and return the survey. As well, employees who did not participate in the study might have had larger or more challenging and timeconsuming caseloads that prevented them from having the time available to complete and return the survey than those with fewer job demands. Second, the response rate (32\%) was somewhat lower than desired. However, the demographic characteristics of respondents were highly similar to other large-scale studies of child welfare professionals in the state with much higher to slightly higher response rates (e.g., Ellett et al., 2003; Ellis et al., 2007). Finally, surveys with excessive missing data were omitted from data analysis. Given the large sample size and the limited effect this had on results, the authors felt this was an appropriate strategy for handling those few surveys with more than $10 \%$ of answers missing.

\section{Implications}

This study has raised several implications for the profession of social work, specifically in the areas of education, practice, and research. First, social work educators could help address the issue of unmet supervisory needs by ensuring that students develop skills in identifying their supervisory needs and skills to advocate for those needs. Social work education could also focus more on teaching students about organizational culture in large agencies, particularly child welfare agencies. Studies of 
professional organizational culture in public child welfare agencies (Ellett, 2000; Ellett et al., 2003) suggest that employees are more likely to remain employed in public child welfare if there is congruence between actual and preferred perceptions of administrative support. In order to better prepare students about the realities of large agencies and better prepare them for the workforce, social work education could include current research on organizational culture and child welfare.

Second, there are several practice implications. Child welfare agencies could focus efforts on improving administrative and supervisory support, particularly for employees with social work education. For instance, agencies could utilize existing research to inform training efforts for administrators and supervisors. Ideally, supervisors should be aware of the varying needs for support of their employees, and facilitate their educational and skill development (Scannapieco \& Connell-Carrick, 2007), as well as attend to their emotional needs (Miseung, 2010). For instance, those without a social work degree may benefit more by supervisory support that focuses on training and education, and those with social work degrees may benefit from equal amounts of supervisory support that focuses on emotional support (Lieberman et al., 1988).

Several explanations could account for the reasons child welfare employees with social work degrees perceived less support from both administrators and supervisors than employees without social work degrees in this study. First, employees with social work degrees may have different expectations or needs from administrators and supervisors. Second, administrators and supervisors could be providing different types and/or amounts of support and supervision to employees with social work degrees than to those without social work degrees. Recommendations for future research that explore these hypotheses are explicated below.

Research has documented a connection between supervisory support, job satisfaction, and intent to leave (Barth et al., 2008; Ellett et al., 2007). In this study, employees with social work degrees perceived less administrative and supervisory support, which may indicate less satisfaction in their job and reduced intentions to remain in the job. Research has also clearly indicated that public child welfare employees with social work degrees have better job performance than those without social work degrees (Barbee et al., 2009a; Barbee et al., 2009b). Therefore, child welfare agencies may be at risk of losing their best performing employees. Future research exploring these possible connections could offer insights into how child welfare agencies might improve retention of employees and outcomes for families and children.

Because several explanations could account for the reasons child welfare employees with social work degrees perceived less support from both administrators and supervisors than employees without social work degrees in this study, future research should compare the supervisory needs of employees with social work degrees with those without social work degrees. Still other research could explore whether administrators and supervisors provide different amounts and types of support to employees with social work degrees and those without.

If employees with social work degrees have different needs and expectations of administrators and supervisors, an explanation could be that through their educational 
training, social workers likely developed expectations of administrators and became familiar with their own supervisory needs. For instance, those with social work education likely enter the job with knowledge that receiving emotional support and support for selfcare can be just as important in a job as receiving case consultation and instrumental support, whereas those without social work degrees would not have this understanding. This hypothesis could be explored in future research studies by exploring and comparing the supervisory and administrative needs of child welfare employees with and without social work degrees.

If social work educated employees have differing needs and expectations than those without social work degrees, it could be because those with social work degrees have identified as social workers through their choice of educational attainment giving them occupational commitment (Landsman, 2001). Therefore, the job and the position of "social worker" is a part of their identity. Whereas those without social work degrees likely see their work in public child welfare as simply a "job," not as an integral part of their identity. Therefore, those with social work degrees might perceive greater need for administrators and supervisors to be involved in promoting a positive public image of the agency. If administrators are not working toward positive community relations and public image, those with social work degrees might feel more slighted by this because of their stronger identification with and commitment to the organization and profession (Ellett et al., 2007; Landsman, 2001; Strolin-Goltzman, McCarthy, \& Caringi, 2007). Research of administrators' efforts in improving public relations and employees' needs and perceptions of those efforts could explore this hypothesis.

The second possible reason that child welfare workers with social work degrees perceived less supervisory support could be that administrators and supervisors provided less support to employees with social work degrees than to those without. Supervisors often believe the most important aspect of their job is teaching and training employees (Ellett, 2006). Employees with social work degrees are typically more competent and effective in their jobs (Barbee et al., 2009a; Scannapieco et al., 2007) and likely are seen as having the knowledge, skills, and abilities to perform the job well. To complicate matters further, those with social work degrees may even seek advice less than employees without social work degrees (Lieberman et al., 1988). Therefore, as bachelor and master level social workers enter positions in child welfare, supervisors and administrators may assume those employees require less time and attention in order to perform their job well. Research is needed to determine if supervisors and administrators provide differing amounts or types of support to employees based on perceived educational differences.

Finally, little research has examined the role of public child welfare administrators overall. Research studies could examine administrator roles, employees' expectations of administrators, and satisfaction with administrative support.

\section{References}

American Public Human Services Association. (2005). Report from the 2004 Child Welfare Workforce Survey: State agency findings. Washington, DC: Author. 
Auerbach, C., McGowan, B. G., \& Heft LaPorte, H. (2008). How does professional education impact the job outlook of public child welfare workers? Journal of Public Child Welfare, 1(3), 55-76. doi:10.1300/J479v01n03-04

Barth, R. P., Lloyd, E. C., Christ, S. L., Chapman, M. V., \& Dickinson, N. S. (2008). Child welfare worker characteristics and job satisfaction: A national study. Social Work, 53(3), 199-209.

Barbee, A. P., Antle, B., Sullivan, D. J., Huebner, R., Fox, S., \& Hall, J. C. (2009a). Recruiting and retaining child welfare workers: Is preparing social work students enough for sustained commitment to the field? Child Welfare, 88(6), 69-86.

Barbee, A. P., Sullivan, D., Borders, K., Antle, B., Hall, C. J., \& Fox, S. (2009b). Evaluation of an innovative social work education model: The Kentucky Public Child Welfare Certification Program (PCWCP). Journal of Social Work Education, 4(3), 427-444.

Child Welfare League of America. (1998). Membership survey. Washington, DC: Author.

Crosson-Tower, C. (2002). Understanding child abuse and neglect ( $5^{\text {th }}$ ed.). Boston, MA: Allyn and Bacon.

Curry, D., McCarragher, T., \& Dellman-Jenkins, M. (2005). Training, transfer, and turnover: Exploring the relationship among transfer of learning factors and staff retention in child welfare. Children and Youth Services Review, 27, 931-948. doi:10.1016/j.childyouth.2004.12.008

Cyphers, G. (2001). Report from the child welfare workforce survey: State and county data findings. Washington, DC: American Public Human Services Association.

Dhooper, S., Royse, D., \& Wolfe, L. (1990). Does social work education make a difference? Social Work, 35(1), 57-61.

Dicksinson, N. S., \& Painter, J. S. (2009). Predictors of undesired turnover for child welfare workers. Child Welfare, 88(5), 187-208.

Dickinson, N. S., \& Perry, R. E. (2002). Factors influencing the retention of specially educated public child welfare workers. Journal of Health and Social Policy, 15(3/4), 89-103.

Drake, B., \& Yadama, G. N. (1996). A structural equation model of burnout and job exit among child protective services workers. Social Work Research, 20, 179-187.

Ellett, A. J. (2000). Human caring, self-efficacy beliefs, and professional organizational culture correlates of employee retention in child welfare. (Unpublished doctoral dissertation, Louisiana State University, 2000). Dissertation Abstracts International, 61, 8-A.

Ellett, A. J. (2006). Broad study but narrow question: A friendly critique of Perry's article. Research on Social Work Practice, 16, 406-411. doi:10.1177/1049731505284204. 
Ellett, A. J., Ellett, C. D., \& Rugutt, J. K. (2003). A study of personal and organizational factors contributing to employee retention and turnover in child welfare in Georgia. Athens, GA: University of Georgia.

Ellett, A. J., Ellis, J., Westbrook, T. M., \& Dews, D. (2007). A statewide qualitative study of 369 professionals: Toward a greater understanding of employee retention and turnover in child welfare. Children and Youth Services Review, 29, 264-281.

Ellis, J. I., Ellett, A. J., \& DeWeaver, K. (2007). Human caring in the social work context: Continued development and validation of a complex measure. Research on Social Work Practice, 17(66), 66-76.

Ewalt, P. L. (1991). Trends affecting recruitment and retention of social work staff in human services agencies. Social Work, 36(3), 214-217.

General Accounting Office. (2003). Child welfare: HHS could play a greater role in helping child welfare agencies recruit and retain staff. (Report to Congressional Requesters). Washington, DC: Author.

Knudsen, D. D. (1988). Child protective services: Discretion, decisions, dilemmas. Springfield, IL: C. C. Thomas.

Landsman, M. (2001). Commitment in public child welfare. Social Service Review, 75(3), 386-419.

Lee, J., Forster, M., \& Rehner, T. (2011). The retention of public child welfare workers: The roles of professional organizational culture and coping strategies. Children and Youth Services Review, 33, 102-109. doi:10.1016/j.childyouth.2010.08.019

Lieberman, A., Hornby, H., \& Russell, M. (1988). Analyzing the educational backgrounds and work experiences of child welfare personnel: A national study. Social Work, 33(6), 485-489.

Miseung, S. (2010). Factors influencing child welfare employee's turnover: Focusing on organizational culture and climate. Children and Youth Services Review, 32(6), 847856. doi:10.1016/j.childyouth.2010.02.004

Risley-Curtiss, C. (2003). Current challenges and future directions for collaborative child welfare educational programs. Journal of Human Behavior in the Social Environment, 7(1/2), 207-226.

Robin, S. C., \& Hollister, C. D. (2002). Career paths and contributions of four cohorts of IV-E funded MSW child welfare graduates. Journal of Health and Social Policy, 15(3/4), 53-67.

Rycraft, J. R. (1994). The party isn’t over: The agency role in the retention of public child welfare caseworkers. Social Work, 39(1), 75-80.

Samantrai, K. (1992). Factors in the decision to leave: Retaining social workers with MSWs in public child welfare. Social Work, 37(5), 454-549. 
Samantrai, K. (2004). Culturally competent public child welfare practice. Pacific Grove, CA: Brooks/Cole-Thomson Learning.

Scannapieco, M., \& Connell-Carrick, K. (2007). Child welfare workplace: The state of the workforce and strategies to improve retention. Child Welfare, 86(6), 31- 52.

Steib, S. D., \& Whiting Blome, W. (2003). Fatal error: The missing ingredient in child welfare reform: Part 1. Child Welfare, 82(6), 747-750.

Strolin-Goltzman, J., Auerbach, C., McGowan, B. G., \& McCarthy, M. L. (2008). The relationship between organizational characteristics and workforce turnover among rural, urban, and suburban public child welfare systems. Administration in Social Work, 3(1), 77-91. doi:10.1300/JI47v32n01_06

Strolin-Goltzman, J., McCarthy, M., \& Caringi, J. (2007). Causes and effects of child welfare workforce turnover: Current state of knowledge and future directions. Journal of Public Child Welfare, 1(2), 29-52. doi:10.1300/J479v01n02_03

U.S. Department of Health and Human Services, Administration for Children and Families, Administration on Children, Youth and Families, Children's Bureau. (2010). Child Maltreatment 2009. Retrieved from http://www.acf.hhs.gov/programs/cb/stats research/index.htm\#can

Westbrook, T. M., Ellis, J., \& Ellett, A. J. (2006). Improving retention among public child welfare workers: What can we learn from the experiences of committed survivors? Administration in Social Work, 30(4) 37-62.

Westbrook, T. M., Ellett, A. J., \& DeWeaver, K. W. (2009). Development and validation of a measure of organizational culture in public child welfare agencies. Research on Social Work Practice, 19(6), 730-741.

\section{Author note:}

Address correspondence to: Tonya M. Westbrook, Department of Social Work, Health and Human Sciences, 4121 Little Savannah Rd., Room 322, Western Carolina University Cullowhee, NC 28723. Email: twestbrook@wcu.edu 